\title{
Electronics and Industrial Development
}

\author{
Ernest Braun
}

\section{Introduction}

A school of thought is beginning to emerge which regards the electronics industry as an essential element in the strategy of building an industrial economy. As in a previous wave of industrialisation in which the steel industry was regarded as fundamental - the foundation upon which other industries could be built - so now the electronics industry has become a symbol of industrial achievement. The reasons for this shift of view are to be found in some features of the electronics industry: its products are extremely varied and are used in an increasing number of other industrial and consumer products; the industry has come to be regarded as the heart of contemporary 'information society'; modern microelectronics and computing are considered crowning achievements of the scientific age.

The electronics industry consists of a variety of disparate sub-branches. In a simplified scheme, we may consider the industry to be divided into electronic components, consumer electronics, industrial electronics, telecommunications, and computers. Each of these subbranches could be further divided. The electronic components industry, for example, manufactures active components, now mostly made of semiconductor materials and therefore known as the semiconductor industry, and passive components, such as resistors, capacitors and circuit boards.

It is very tempting to think of the semiconductor industry as the true cornerstone of an industrialisation strategy, because it lies at the heart of the electronic industry by providing the bulk of its active components. It is easy, but wrong, to identify the electronics industry with the manufacture of semiconductor devices. It is equally easy, and equally wrong, to confuse achievement in the semiconductor industry with the attainment of the general goals of industrialisation. It is not the purpose of this article to rehearse the wellknown arguments in favour of industrial production as an economic activity supplementary to agricultural and mineral production, but rather to examine the electronics industry, and particularly the semiconductor industry, to illuminate its potential as a cornerstone of a policy for industrial development.

\section{The semiconductor industry}

The products of the semiconductor industry range from rectifiers and transistors, the so-called discrete components, to a large variety of integrated circuits of varying sophistication, right up to the most advanced microprocessors and memory chips and special purpose circuits. There are several very specific features of the semiconductor industry which distinguish it from other industrial branches. The main features are: high capital intensity; very high sophistication and dependence upon rare specialised scientific and engineering skills; high degree of interdependence within the industry and with specialist suppliers; and dominance of US know-how and US markets.

Although the semiconductor industry provides a prime example of the successful entry and growth of very small entrepreneurial firms, it also provides a classic example of maturation of an industry. In the early days of the industry, a few bright ideas, a little capital and plenty of hard work went a long way toward success. Many of the firms which started from scratch in the 1950s and 1960 s have become industrial leaders, although many have failed to make the grade and have disappeared into oblivion. The capital required to enter the industry has become steadily larger, especially the entry fee into the select club of companies producing very large-scale integrated curcuits (vlsi). INMOS, the company funded by British public funds through the British Technology Group (formerly the National Enterprise Board) has $£ 50 \mathrm{mn}$ as its starting capital. This sum should prove just sufficient to give the company a chance to become a major competitor in advanced memory and microcomputer chips.

Not only is the entry fee into the semiconductor industry high: it has become a capital intensive industry in every sense of the word. Continued need for high capital investment has caused even some of the most successful firms to run into cash-flow problems and to become prone to being taken over by industrial giants with plenty of cash. Many a proud success of entrepreneurial skill of the 1950s and 1960s has now become a member of some major international group whose origins lie in the dim past of industrial history. 
With increasing capital intensity, the industry is, of course, becoming less labour intensive and, to compound this problem, its labour requirements are mostly for people with highly specialised skills. For despite this apparent maturity of the industry after about 30 years of existence, its products and production methods are still changing very fast, and this change is backed by a vast army of scientists, engineers and technicians working in research, development and design.

Design has become a major preoccupation of the industry, taking its place at the side of the old preoccupation with yield of good chips per processed wafer. There are two major avenues of design: optimal chip design for mass produced circuits and design of special chips for relatively specialised applications. Additionally, there is the compromise of 'customised' design, using either standard chips or so-called undedicated logic arrays. The design of the latest microprocessors on the market takes between 100 and 200 person years of effort, despite the use of incredibly sophisticated computer aids. Computer designs computer, but not without the massive intervention of teams of highly trained, highly skilled, highly educated designers, ideally headed by chief designers of true genius. All this enormous design effort is spent in order to make a chip of the highest performance at the lowest possible price-for competition is extremely severe and neither inferior performance nor a premium price are tolerated by the market.

The more specialised applications are slightly easier to cater for. The design aims to achieve the function without optimal use of silicon, as the price is relatively unimportant. The design process consists of selecting pre-designed building blocks--stored in the computer - and interconnecting them suitably. An extreme case of this approach is to have semi-finished chips with arrays of logic gates - the building blocks referred to above - and leave the final interconnecting stage to determine what sort of device it shall be. It is even possible for sophisticated groups of specialists requiring specialised chips to produce their own design and have it made by a chip manufacturer in small numbers. Hence the concept of the 'silicon foundry', an analogy with the casting to order of a customer's model in metal working industries.

The number of firms capable of doing all, or even some, of these things is quite small and the mobility of people within the industry is quite high. There is of course a premium on know-how; yet there is a surprising degree of sharing of general information. Everybody in the industry knows everybody else, and everyone knows the general drift of things to come. The state of the art and its short-term development are shared knowledge among the initiated - competitive advantage is gained by being just that little bit better that little bit sooner.

The vast amount of research effort does, of course, produce a large number of new devices and, infinitely more important, new ways of making new devices. Much of the vital detail of this information is kept confidential. Anything that cannot be kept secret is covered by patents and there is a lively trade in patent licences amongst all the manufacturers. The aim of the game is to exchange licences, rather than pay licence fees. Only by having a valuable portfolio of patents is it possible to make sure that other people's vital patents will be available when required.

All these features show an extraordinary degree of interdependence within the industry. Fierce competitors they may be, but they all know that they are in this business together. But who are they? Predominantly the American semiconductor industry, with the Japanese, after years of strenuous effort, now just about joining in as equal partners. A small handful of European firms are also now among the important semiconductor manufacturers, but there is no doubt that they gained this status by purchasing American firms and thus joining the semiconductor community on its home ground. The current leaders of the industry are listed in Table 1.

Another aspect of interdependence, true of industry in general but especially marked in the most advanced industries, is the dependence of each manufacturer upon a host of specialist suppliers. The manufacture of integrated circuits requires raw materials, chemicals, scientific instruments, optical and mechanical equipment and many other advanced items of great sophistication. In order to keep up with developments, the manufacturer must be in constant dialogue with his suppliers - a two way traffic of ideas and possibilities. An industrial system is in fact just that - a network of interconnected units each dependent on many others. This aspect of industry makes industrial development much harder, particularly in the most advanced industries.

Although all the glamour seems to be in the manufacture of the most sophisticated integrated circuits, much of the business is still in more technologically 'stable' discrete components and integrated circuits with few components. The market for discrete components is quite substantial and their manufacture is also becoming more sophisticated. Nonetheless, this is the simpler part of the business and might still be accessible to new entrants, especially if these were aided by some protective measures.

On the whole, it seems quite clear that to enter into the manufacture of very highly integrated circuits is 
Shares of world semiconductor markets of 19 largest companies, excluding captive production, 1978

\begin{tabular}{|c|c|c|c|}
\hline \multirow[t]{2}{*}{ company } & \multirow[t]{2}{*}{ base } & \multicolumn{2}{|c|}{ market share \% } \\
\hline & & $\begin{array}{c}\text { all } \\
\text { semiconductor }\end{array}$ & $\begin{array}{l}\text { integrated } \\
\text { circuits }\end{array}$ \\
\hline Texas Instruments & US & 10.5 & 13.1 \\
\hline Motorola & US & 7.8 & 6.4 \\
\hline Philips $^{1}$ & Netherlands & 7.8 & 7.3 \\
\hline Nippon Electric & Japan & 5.8 & 5.8 \\
\hline Hitachi & Japan & 5.8 & 5.0 \\
\hline National Semiconductor & US & 4.8 & 7.1 \\
\hline Toshiba & Japan & 4.4 & 3.7 \\
\hline Fairchild & US & 4.1 & 4.9 \\
\hline Intel & US & 3.4 & 5.8 \\
\hline Siemens $^{2}$ & Germany & 3.3 & 2.0 \\
\hline Matsushita & Japan & 2.9 & 1.7 \\
\hline $\mathrm{RCA}$ & US & 2.7 & 2.5 \\
\hline ITT & US & 1.9 & 1.4 \\
\hline Mitsubishi & Japan & 1.7 & 1.4 \\
\hline American Micro Devices & US & 1.5 & 2.5 \\
\hline Thomson CSF & France & 1.5 & 0.6 \\
\hline Mostek & US & 1.4 & 2.4 \\
\hline Fujitsu & Japan & 1.4 & 1.8 \\
\hline General Instrument & US & 1.4 & 1.4 \\
\hline Collective share of world market & & 74.1 & 76.8 \\
\hline \multicolumn{4}{|l|}{${ }^{1}$ including Signetics in US } \\
\hline${ }^{2}$ including Dickson in US & & & \\
\hline
\end{tabular}

Source: Dataquest, 19 February 1980

just about the most difficult and least effective way of entering industrial production. The dice are loaded against the newcomer with a small home market, short of capital, short of skilled manpower and rich only in unskilled labour. The disadvantages become less formidable as one goes down the scale from massive integration, to special purpose integrated circuits, to discrete semiconductor components. But if less formidable the going is still tough, and the rest of the electronics industry may provide better opportunities than active semiconductor components.

\section{Consumer electronics}

The consumer electronics industry uses electronic and other components to assemble electronic goods for final consumption by a mass market, eg radio receivers, television receivers, pocket calculators, tape recorders. By its very nature, this industry does a lot of assembly work which can be quite labour intensive. The range of components a manufacturer produces internally as opposed to buying in can vary greatly, and the degree of sophistication of the products also covers a wide range, from simple radios to complex video recorders. Clearly a domestic industry can start from almost pure assembly of simple equipmentachieving mainly import substitution and some employment - and can gradually build up expertise to widen the range of both home produced components and final products.

With the right policies, giving high priority to training and a gradual shift from assembling foreign parts to truly home based manufacture, the consumer electronics industry can go beyond mere import substitution to genuine industrial development. The value added in this industry consists, at least in large part, of relatively simple operations, whereas in semiconductor manufacture, value is added almost entirely in complex processes. In consumer electronics there are many degrees of choice-from simple assembly of simple products to full manufacture of components and the assembly of elaborate products. Ready access to a substantial home market is a further point in favour of consumer electronics as a starting point for an electronics industry. 


\section{Industrial electronics and computers}

Much that has been said about consumer electronics applies to industrial electronics. The range of products in this sector is very large, but assembly plays a substantial role in the production process. The main difference between the two sectors lies in the market - while one caters for personal consumption, the other caters for industrial users. Clearly, the latter market depends on industrial needs, and marketing can only be done by very close contact between potential user and potential supplier. In fact the industrial electronics sector is typically part of the industrial user supplier system, which depends on close links and a good flow of information. The success of an industrial electronics sector thus depends not only on what other industry exists, but also on the level of cooperation between the electronics sector and the other industrial sectors.

As process control and other industrial applications of electronics depend on the use of microprocessors, which can be bought quite cheaply on the world market, technical success depends on clever design of software and on sensors, actuators and system engineering. The production of application specific software is one of the cornerstones of industrial electronics, and competence in it can bypass the need for very specialised components. Training in systems engineering and programming are thus essential ingredients in the development of an indigenous industrial electronics sector.

The computer industry has become an almost separate sector, and it too spans a very wide range of products. There are the industrial giants producing large, very expensive and very sophisticated mainframe computers. This industry is almost comparable to the aircraft industry - only a very few international giants can supply all the needs, and competing with them is quite impossible. On the other hand, there are now hundreds of small manufacturers producing very small and often very simple computers ranging from the consumer-oriented home computer to the more sophisticated machine aimed at the small business. In between is a range of medium-sized computers used in larger office applications, in industrial control, in distributed modes where several smaller computers add up to quite a large installation, in scientific work and in many other ways. The rules of the computer would seem to be that today's smaller machine can do what yesterday's larger one could, but at very much lower cost.

From this, it would appear that entry into the computer industry is really only possible at the lower end of the market. At that end, a few clever systems designers and programmers can go a long way towards a viable product. The production consists largely of assembling bought-in parts, with only a few specially fabricated for the particular application.

Before leaving the electronics industry itself to discuss the implications of electronics for the performance of other industries in world markets, the question of 'strategic dependence' must be raised. It has been argued that any country aspiring to the status of an industrial power must have its own capability for the manufacture of semiconductor devices, including very large scale integrated circuits. This argument is based on the assumption that the semiconductor industry is fundamental to all other industries because semiconductors lie at the heart of electronics, and electronics is at the heart of much modern equipment and machinery. The argument goes on to assert that no country can afford to depend on any other for the supply of something as vital as semiconductor devices because supplies might be cut off and because domestic design becomes dependent on crucial foreign inputs.

There are numerous counter arguments to making semiconductors the cornerstone of a strategy of industrial independence. For although semiconductors may be seen as fundamental, they are not a good foundation on which to build industry. The industrial and economic system of any country is linked in multiple ways to the world economic system, and it is hard to see why dependence in the semiconductor area should be worse than dependence in any other-energy, metallurgy, plastics, pharmaceuticals, food, machine tools. In any case, the semiconductor industry itself is dependent on a vast variety of inputs, from silicon crystals to advanced photographic chemicals to computer-aided design. It would verge on the fantastic to believe that any small or medium country could build up the full range of industrial and service facilities required to run a modern, self-sufficient semiconductor industry. In any case, it is no more likely that the world market in semiconductors should become closed to any particular country than that any other market should become closed. Why should it be more acceptable to depend on the world market for chrome, or paper, or penicillin, or fighter planes, than for integrated circuits?

\section{Microelectronics in industry}

Microelectronic devices, that is integrated circuits and associated electronic components forming compact devices for the performance of a variety of tasks, have spread into many uses. The main functions performed by such devices are the storage and manipulation of information. Information may consist of anything that a suitable transducer can transform into a series of electrical signals. Thus the values of physical and chemical variables, such as specific gravity or 
temperature, may be regarded as information; details of an engineering drawing may be stored as information; and so, of course, may verbal or numerical information. Because the manipulation, storage, display and transmission of information is an important economic activity in itself and also underlies activities such as manipulation of materials, control of processes and shaping of artefacts, microelectronic devices have penetrated into a wide range of economic activities.

We use computers of all shapes and sizes, from mainframe universal computers to specialised applications of microprocessors, to handle office information and administration data, to control machine tools, to control robots for the handling of materials or tools such as spot welding guns, in telephone exchanges, in process controllers from chemical plant to domestic central heating. Perhaps the lumping together of so many varied applications of microelectronics in a short paragraph may serve to highlight two essentially different features of the technology: - it can save labour in labour intensive occupations in handling and assembling materials or information, and it can enhance the performance and quality of some products.

Clearly, labour saving is advantageous only if an overall saving in cost is achieved or if there is a particular shortage of labour. Such a shortage may exist even when there is no general shortage, and may concern some particular skills, or the unwillingness of labour to perform some unpleasant task. In general, the labour saving capability of microelectronics will rarely give a strong competitive advantage to developing countries. In fact the reverse is true: labour saving by electronics in advanced countries may erode the competitive advantage of cheap labour in some activities in developing countries. Occasionally labour saving is so great that it makes a task possible which previously might have been virtually impossible. This applies mainly to the capabilities of large computers to sort and sift large quantities of information which would defy an army of clerks.

The enhancement of the performance and quality of products is the one aspect of microelectronics which nobody can ignore. If, for example, the engines in some motor cars are electronically controlled and this improves their performance in a cost effective way, then after a short time no manufacturer of car engines can remain in an internationally competitive business without achieving comparable performance at similiar cost. The substitution of electronic controls for electromechanical devices in telephone exchanges, typewriters and process controllers of all kinds falls into the same category - a superior technology at advantageous cost cannot be ignored without erosion of competitive position.

\section{Comparative advantage}

The crux of any industrial strategy must be comparative advantage. But because comparative advantage depends upon particular circumstances of time and place, only very broad generalisations are possible and detailed decisions must vary from place to place and time to time.

Multinational corporations can often be induced to place some parts of their manufacture of semiconductors and electronics in developing countries. This can be worthwhile if it provides employment and foreign exchange, but it can be infinitely more worthwhile if it also provides a training ground for skilled labour and promotes further economic development by local purchases of supplies and services. The degree of off-shore involvement of the corporations varies from time to time, as the labour intensity of processes changes and with economic incentives on offer. Currently, automation in the production of semiconductor devices seems to be increasing and therefore the scope for off-shore activities is decreasing. For discrete components and electronic equipment the situation is somewhat different and there is scope for investment by multinational corporations. The benefits from such investment are undoubtedly subject to local policies and circumstances.

Developing countries have the advantage of cheap and willing labour, and this can be an incentive for locating relatively labour intensive operations. Whether such operations are financed by foreign or home based corporations, the main economic benefit to a country must come through training and infrastructural developments. This is why the advantages of consumer and industrial electronics were stressed earlier. For in these industries it is possible to take advantage of labour intensive assembly, and yet build up expertise in electronics and gradually increase the domestic component in the total value added.

As comparative advantage is so specific to time and place, the only principle that can be enunciated is the need to seek out comparative advantage and, as a corollary, to avoid comparative disadvantage. 